\title{
Perfil de sensibilidad in vitro de Staphylococcus spp. aislados de muestras en pioderma canino en la ciudad de Popayán
}

In vitro sensitivity profile of Staphylococcus spp. isolated from samples in canine pyoderma in the city of Popayán

Perfil de sensibilidade in vitro de Staphylococcus spp. isolado de amostras em piodermite canina na cidade de Popayán

\author{
Adriana Celis-Enríquez, $\mathrm{MV}_{1}$ \\ Nasly D Chantre-Gonzalez, MV \\ Estephany Gaviria-Bejarano, $\mathrm{MV}_{1}$ \\ Carmen Alicia Daza-Bolaños, $\mathrm{PhD}_{2}$
}

Recibido: 31 de julio de 2019

Aprobado: 13 de octubre de 2020 Publicado: 30 de noviembre de 2020

Cómo citar este artículo:

Celis-Enríquez A, Chantre-Gonzalez ND, Gaviria-Bejarano E, Daza-Bolaños CA. Perfil de sensibilidad in vitro de Staphylococcus spp. aislados de muestras en pioderma canino en la ciudad de Popayán. Spei Domus. 2020;16(1): 1-13. doi: https://doi.org/10.16925/2382-4247.2020.01.02

Artículo de investigación. https://doi.org/10.16925/2382-4247.2020.01.02

1 Facultad de Medicina Veterinaria y Ciencia Animal, Universidad Antonio Nariño, Colombia.

2 Facultad de Medicina Veterinaria y Ciencia Animal, Universidad Antonio Nariño, Popayán, Cauca. Calle 53N \#9-35. Teléfono (092) 8326147.

Correo electrónico: carmen.dazab@uan.edu.co 


\title{
Resumen
}

El pioderma canino corresponde a la contaminación bacteriana de la piel, causada en mayor parte de los casos por Staphylococcus pseudointermedius. Durante las últimas décadas los Staphylococcus spp. han mostrado una mayor resistencia a los antimicrobianos, en medicina humana y veterinaria. El objetivo del presente estudio fue determinar el perfil de sensibilidad in vitro de Staphylococcus spp. aislados en muestras de pioderma canino en la ciudad de Popayán. Fueron colectadas 34 muestras de caninos diagnosticados con pioderma en clínicas y refugios, cultivadas en medio de agar suplementado con sangre de oveja al $5 \%$ e incubadas a $37{ }^{\circ} \mathrm{C}$ en condiciones de aerobiosis. Colonias aisladas se sometieron a pruebas primarias como tinción de Gram y posteriormente se clasificaron por métodos bioquímicos: catalasa, manitol, fermentación de maltosa, glucosa y sacarosa. El perfil de sensibilidad fue evaluado por el método de difusión en discos con los antibióticos ceftriaxona, cefalexina, amoxicilina con ácido clavulánico, doxiciclina, clindamicina y trimetoprim/sulfametoxazol, clasificando a los estafilococos como sensibles, intermedios o resistentes con referencia en los valores del Clinical and Laboratory Standard Institute. En $38 \%$ de las muestras cultivadas $(n=13)$ fue aislado S. pseudointermedius, $18 \%(n=6)$ S. epidermidis, $15 \%(n=5)$ S. intermedius, $12 \%(n=4)$ S. aureus y en $18 \%(n=6)$ otros estafilococos. Respecto al perfil de sensibilidad in vitro, en términos generales se observó una mayor resistencia frente a clindamicina (68\%), cefalexina (68\%), amoxicilina/ácido clavulánico (59\%) y ceftriaxona (56\%). Respecto al patógeno más resistente, S. pseudointermedius mostró una resistencia en 6/13 aislados para todos los antibióticos evaluados, seguido de $S$. epidermidis con $5 / 6$ aislados y $S$. intermedius con $3 / 5$ aislados. S. aureus, y Staphylococcus spp. mostraron igual proporción de muestras resistente y sensibles dentro del total de aislados. El uso de pruebas específicas como cultivo y antibiograma es útil para identificar el patógeno causante y establecer una antibioterapia adecuada.

Palabras clave: antibiograma, pioderma canino, Staphylococcus spp. resistencia antimicrobiana.

\begin{abstract}
The canine pyoderma refers to bacterial contamination of the skin, caused in most cases by Staphylococcus pseudointermedius. During the last decades the Staphylococcus spp. have shown greater resistance to antimicrobials, in human and veterinary medicine. The objective of the present study was to determine the "in vitro" sensitivity profile of Staphylococcus spp. isolated in samples of canine pyoderma in the city of Popayán. 34 samples of canines diagnosed with pyoderma were collected in clinics and shelters, grown in $5 \%$ blood agar medium and incubated at $37^{\circ} \mathrm{C}$ in aerobiosis. Isolated colonies were stained with Gram method and classified by biochemical methods: catalase, mannitol, maltose fermentation, glucose and sucrose. The sensitivity profile was evaluated by the method of diffusion in discs with the antibiotics, ceftriaxone, cephalexin, amoxicillin/ clavulanic acid, doxycycline, clindamycin and trimethoprim/sulfametoxazol, classifying staphylococci as sensitive, intermediate or resistant with reference to the values of the Clinical and Laboratory Standard Institute. In $38 \%$ of the cultured samples $(n=13)$ S. pseudointermedius, $18 \%(n=6)$ S. epidermidis, $15 \%(n=5) S$. intermedius, $12 \%(n=4)$ S. aureus was isolated and in $18 \%(n=6)$ other staphylococci. Regarding the "in vitro" sensitivity profile, in general terms, a greater resistance to clindamycin (68\%), cephalexin (68\%), amoxicillin / clavulanic acid (59\%) and ceftriaxone (56\%) was observed. Regarding the most resistant pathogen, S. pseudointermedius showed resistance in $6 / 13$ isolates for all antibiotics evaluated, followed by $S$. epidermidis with $5 / 6$ isolates and $S$. intermedius with $3 / 5$ isolates. S. aureus, and Staphylococcus spp. they showed the same proportion of resistant and sensitive samples within the total of isolates. The use of specific tests such as culture and antibiogram is useful to identify the causative pathogen and establish adequate antibiotic therapy.
\end{abstract}

Keywords: Antibiogram, Staphylococcus, canine pyoderma, antimicrobial resistance. 


\section{Resumo}

O pioderma canino corresponde à contaminação bacteriana da pele, causada na maioria dos casos por Staphylococcus pseudointermedius. Nas últimas décadas, o Staphylococcus spp. demonstraram maior resistência aos antimicrobianos na medicina humana e veterinária. 0 objetivo do presente estudo foi determinar $\mathrm{o}$ perfil de sensibilidade "in vitro" de Staphylococcus spp., isolado em amostras de pioderma canino na cidade de Popayán. 34 amostras de caninos diagnosticados com pioderma foram coletadas em clínicas e abrigos, cultivadas em meio de ágar sangue a $5 \%$ e incubadas a $37{ }^{\circ} \mathrm{C}$ em condições de aerobiose. Colônias isoladas foram coradas pela tinção de Gram e classificadas por métodos bioquímicos: catalase, manitol, fermentação de maltose, glicose e sacarose. 0 perfil de sensibilidade foi avaliado pelo método de difusão em discos com antibióticos ceftriaxona, cefalexina, amoxicilina/ácido clavulánico, doxiciclina, clindamicina e trimetoprim/ sulfametoxazol, classificando os estafilococos como sensíveis, intermediários ou resistentes, com referência aos valores da Clínica e Laboratory Standard Institute. Em $38 \%$ das amostras cultivadas $(n=13)$ S. pseudointermedius, $18 \%(n=6)$ S. epidermidis, $15 \%(n=5)$ S. intermedius, $12 \%(n=4)$ S. aureus foi isolado e em $18 \%$ $(n=6)$ outros estafilococos. Em relação ao perfil de sensibilidade "in vitro", em termos gerais, observou-se maior resistência à clindamicina (68 \%), cefalexina (68 \%), amoxicilina / ácido clavulânico (59 \%) e ceftriaxona (56\%). Respeito do patógeno mais resistente, S. pseudointermedius apresentou resistência em 6/13 isolados para todos os antibióticos avaliados, seguido por $S$. epidermidis com $5 / 6$ isolados e $S$. intermedius com $3 / 5$ isolados. S. aureus, e S. Staphylococcus spp. mostraram a mesma proporção de amostras resistentes e sensíveis no total de isolados. 0 uso de testes específicos, como cultura e antibiograma, é útil para identificar o patógeno causador e estabelecer terapia antibiótica adequada.

Palavras chave: antibiograma, Staphylococcus spp, pioderma canino, resistência antimicrobiana.

\section{Introducción}

Los problemas dermatológicos son muy habituales en la clínica veterinaria de animales de compañía [1]. La piel posee una microbiota que está constituida por microorganismos saprófitos cuya población permanece latente, pero hay algunos que son transitorios y pueden llegar a la piel lesionada a partir de las mucosas superficiales del animal o desde el medio ambiente, generándose un desequilibrio que permite la proliferación de microorganismos oportunistas y la instalación de la infección [2].

El pioderma es una afección bacteriana piógena de la piel, que se encuentra entre las afecciones dermatológicas más comunes en los perros [3]. A pesar de su prevalencia y apariencia clínica a menudo típica, algunos casos presentan desafíos de diagnóstico incluso para los médicos experimentados. Estas dificultades pueden presentarse por el desarrollo de lesiones clínicas únicas, la presencia de un agente etiológico inesperado o por un parecido cercano con otra enfermedad [2].

Staphylococcus spp es un género de microorganismos constituido por cerca de 40 especies diferentes, que se aíslan a partir de mucosas y piel en mamíferos [4]. A pesar de que forman parte de la flora normal de la piel, bajo determinadas condiciones pueden comportarse como patógenos. Las principales especies patógenas en el 
hombre y en los animales de compañía, S. aureus, S. pseudointermedius y S. hyicus, son capaces de sintetizar el enzima coagulasa (especies coagulasa positivas). Las especies coagulasa negativas, S. epidermidis, S. saprophyticus, se comportan como comensales, llegando a causar infecciones de forma muy ocasional en animales de compañía [5]. El pioderma es una de las principales presentaciones que conducen a la prescripción de antimicrobianos en la práctica de pequeños animales [6].

El control del pioderma canino se basa en la terapia antimicrobiana local o sistémica. Sin embargo, en los últimos años se ha observado un aumento mundial en la prevalencia de resistencia a los agentes antimicrobianos de uso común [7], lo que representa un desafío para el éxito de una terapia.

Dentro del género Staphylococcus, la resistencia a la meticilina ha sido la más reportada no solamente por S. aureus sino también por S. pseudointermedius, actualmente, el agente más común de pioderma en caninos [8]. Adicionalmente, varios estudios han reportado el surgimiento de cepas resistentes a otros antibióticos [5, 9].

Por lo anterior, el objetivo de este estudio fue determinar el perfil de sensibilidad in vitro de Staphylococcus spp. aislados en muestras de pioderma canino, en la ciudad de Popayán.

\section{Animales y colecta de muestras}

Las muestras se obtuvieron de 34 caninos hembras y machos de diferentes edades y razas, provenientes de consultorios veterinarios y refugios a partir de lesiones sugestivas de pioderma (costras, pápulas, pústulas). Paciente que estuviera recibiendo tratamiento antibiótico, inclusive por causas diferentes a pioderma, al menos en un periodo de cuatro semanas previas a la colecta, no se vinculó al estudio. La colecta se realizó con hisopo estéril con medio de transporte Stuart ${ }^{\circledR}$ y transportado en neveras isotérmicas $\left(4^{\circ} \mathrm{C}\right)$ para su procesamiento en un período de 24 horas. En caso de lesiones pustulosas se realizó colecta aspirando el contenido en una jeringa estéril.

\section{Aislamiento y clasificación de Staphylococcus spp.}

Las muestras fueron cultivadas en agar suplementado con sangre ovina (5 \%) e incubadas en condiciones de aerobiosis a $37{ }^{\circ} \mathrm{C}$, mantenidas hasta por 48 horas, con lecturas cada 24 horas para verificar crecimiento [10]. Las colonias sugestivas de Staphylococcus fueron sometidas a tinción de gram y prueba de catalasa, 
posteriormente, se cultivaron en medios selectivos y diferenciales como Agar Sal Manitol, se realizó prueba de coagulasa utilizando plasma de conejo y fueron sometidas pruebas bioquímicas basadas en la fermentación de azúcares como maltosa, sacarosa, glucosa (1\%) [11], dejando en incubación a $37^{\circ} \mathrm{C}$ por 12 horas.

\section{Perfil de sensibilidad in vitro}

Los microorganismos aislados fueron sometidos a la prueba de sensibilidad in vitro por el método de difusión en discos [12], evaluando los siguientes antibióticos, empleados para el tratamiento de pioderma canino: ceftriaxona (CRO) $30 \mu \mathrm{g}$, cefalexina

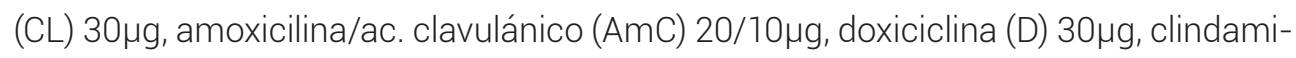
cina (DA) $2 \mu \mathrm{g}$ y trimetoprim/sulfametoxazol (CXT) 25 $\mu \mathrm{g}$.

Una vez se confirmó la presencia de Staphylococcus spp. en las muestras cultivadas, se procedió a preparar el inóculo tomando una colonia y repicándola en caldo cerebro-corazón (BHI), dejando en incubación por 6-8 horas aproximadamente. La turbidez de la muestra se comparó con la escala de MacFarland tubo número 5

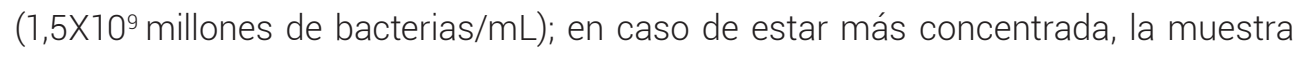
se diluyó con solución salina estéril y se comparó nuevamente con la escala. A continuación, se inoculó en una placa de agar Mueller-Hinton, asegurando que toda la placa quede cubierta por el inóculo y se colocaron los discos impregnados con los antimicrobianos a ser evaluados. Las placas se incubaron a $37^{\circ} \mathrm{C}$ por 12 horas. La interpretación de las lecturas de los halos se realizó con base en el manual del Clinical and Laboratory Standars Institute (CLSI) [12].

\section{Resultados}

\section{Caracterización de los animales objeto del estudio y lugar de muestreo}

La muestra estudiada se caracterizó por ser relativamente joven, ya que 21 (62 \%) de los pacientes evaluados se encontraban en un rango de edad entre los 1 y 4 años, ocho (24\%) caninos entre los 4 y 8 años y cinco caninos (15\%) estaban por encima de los ocho años. Respecto a la raza, la que predominó fue mestiza con un $53 \%$ del total de los animales evaluados, seguido de la raza pitbull y labrador, con un $15 \%$ y $12 \%$, respectivamente, y en menor proporción las razas Beagle (9 \%), Boston terrier (3\%), Sharpei (3\%) y West Highland (3\%). En cuanto a la distribución por sexo, se encontró 
Perfil de sensibilidad in vitro de Staphylococcus spp. aislados de muestras en pioderma canino en la ciudad de Popayán

que predominaron las hembras puesto que de los animales 34 animales muestreados, 24 (71\%) fueron hembras.

Las muestras obtenidas para el presente estudio, fueron provenientes en su mayoría de refugios de la ciudad (23/34) comparado con el número de muestras colectadas de consultorios veterinarios (11/34).

\section{Especies de estafilococos identificadas en las muestras de pioderma analizadas}

Los casos predominantes encontrados de acuerdo al tipo de estafilococo se centran en los S. pseudointermedius, ya que 13 de los 34 animales analizados presentan este tipo de diagnóstico, a él se le suman los S. epidermis con el $18 \%$ de la población (figura 1).

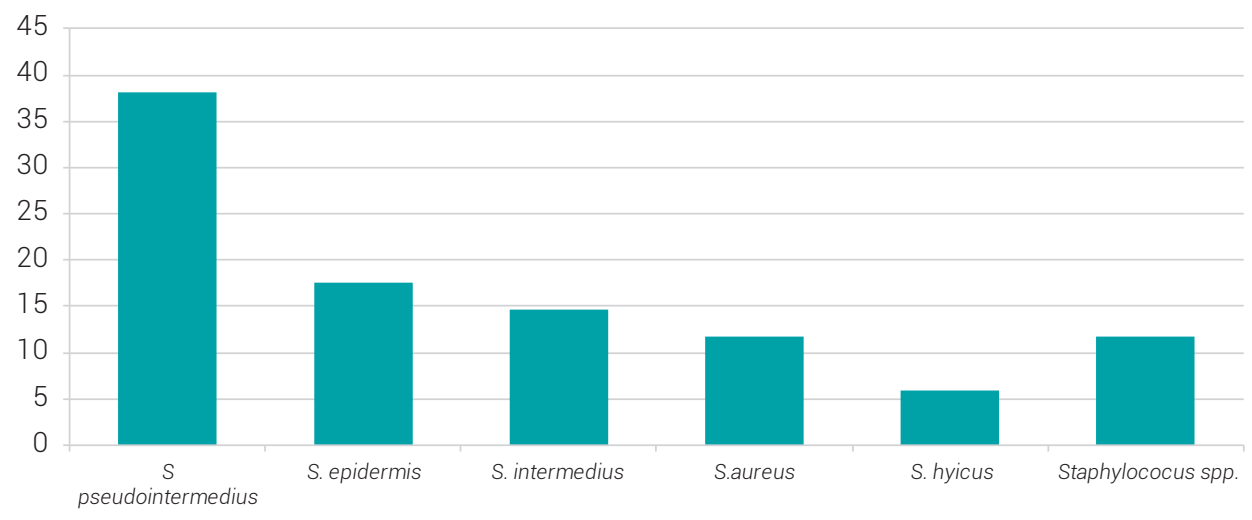

Figura 1. Porcentaje de Staphylococcus spp. aislados en muestras de pioderma canino en la ciudad de Popayán

Fuente: elaboración propia

\section{Perfil de sensibilidad in vitro de los Staphylococcus identificados}

El perfil de sensibilidad de Staphylococcus aureus frente a los antibióticos evaluados fue similar en los cuatro aislados respecto a los seis antibióticos, excepto clindamicina, donde una muestra fue resistente, dos fueron sensibles y una con sensibilidad intermedia (figura 2). 
Adriana Celis-Enríquez, MV, Nasly D Chantre-Gonzalez, MV, Estephany Gaviria-Bejarano, MV, 7 Carmen Alicia Daza-Bolaños, PhD

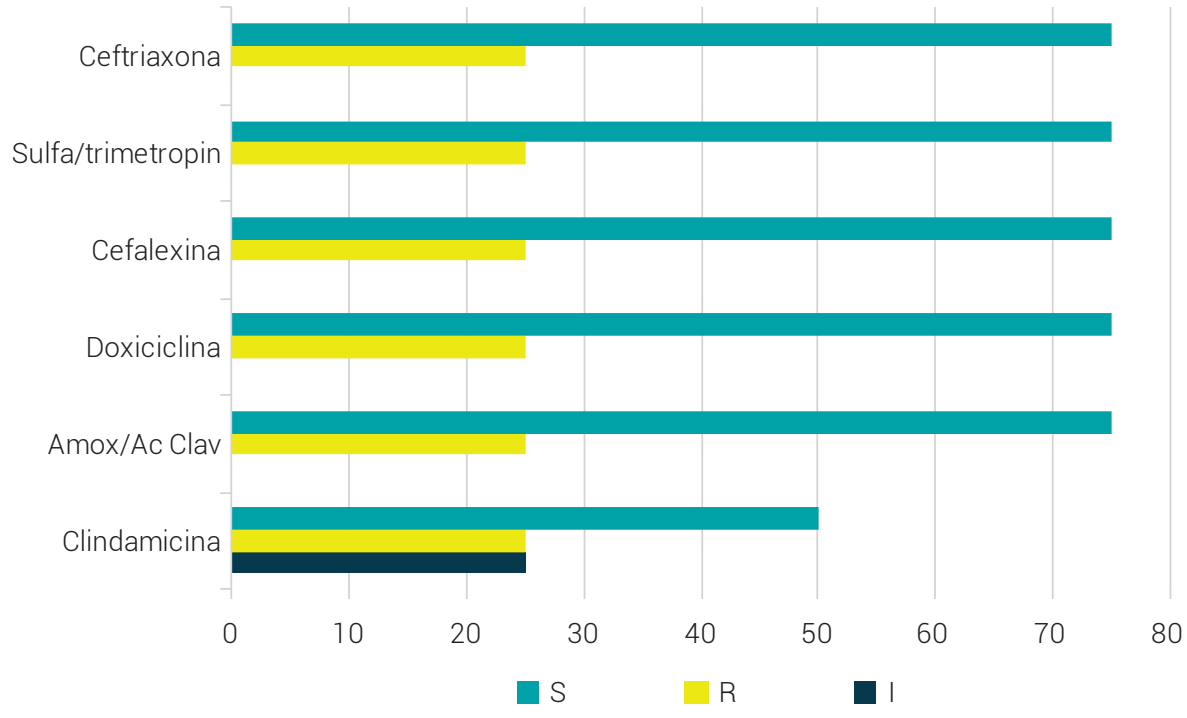

Figura 2. Perfil de sensibilidad de muestras identificadas con Staphylococcus aureus aislado de muestras de pioderma canino en la ciudad de Popayán

Fuente: elaboración propia

Respecto al perfil de sensibilidad de Staphylococcus pseudointermedius, de los 13 aislados identificados, 10 (77\%) fueron resistentes a clindamicina, con referencia a los betalactámicos evaluados y a trimetoprim/sulfametoxazol, aproximadamente el 50 \% de los aislados fue resistente. Únicamente para doxiciclina 9 (69\%) de los aislados fueron sensibles (figura 3).

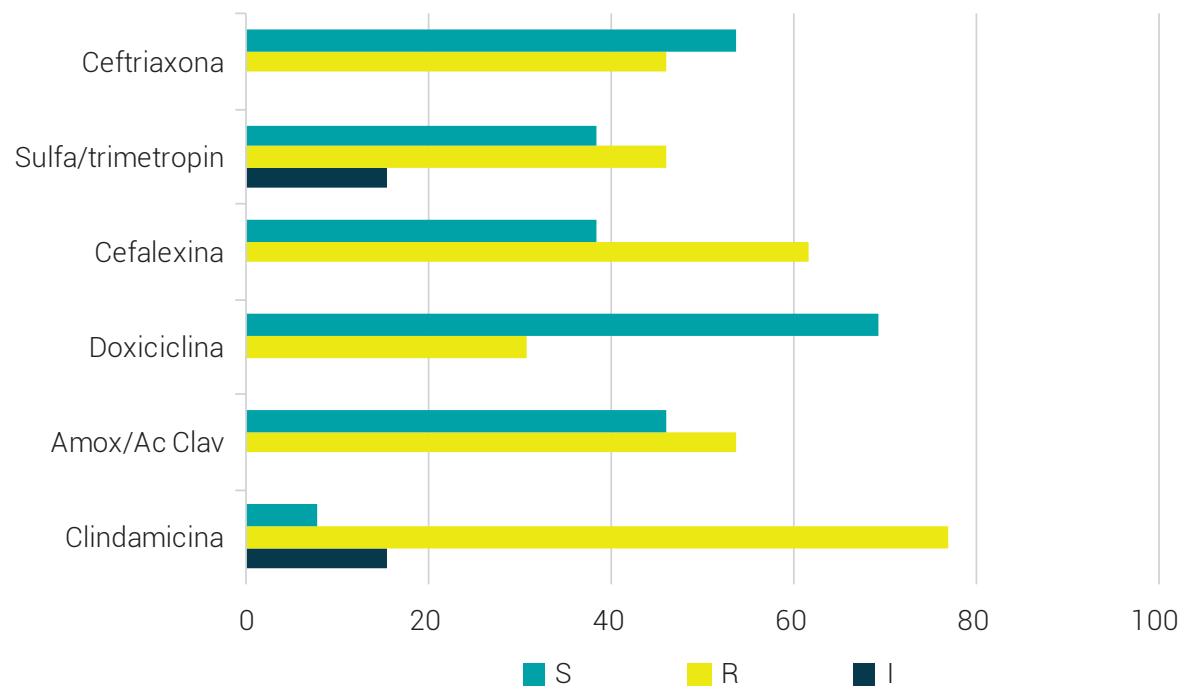

Figura 3. Perfil de sensibilidad de muestras identificadas con Staphylococcus pseudointermedius aislado de muestras de pioderma canino en la ciudad de Popayán

Fuente: elaboración propia 
8 Perfil de sensibilidad in vitro de Staphylococcus spp. aislados de muestras en pioderma canino en la ciudad de Popayán

Las muestras identificadas como S. epidermidis expusieron un patrón de resistencia similar a los anteriores estafilococos, donde únicamente para doxiciclina hubo sensibilidad del 100 \%. Para los otros antibióticos evaluados se observó una resistencia del 50 \% hasta el $100 \%$ en las muestras (figura 4).

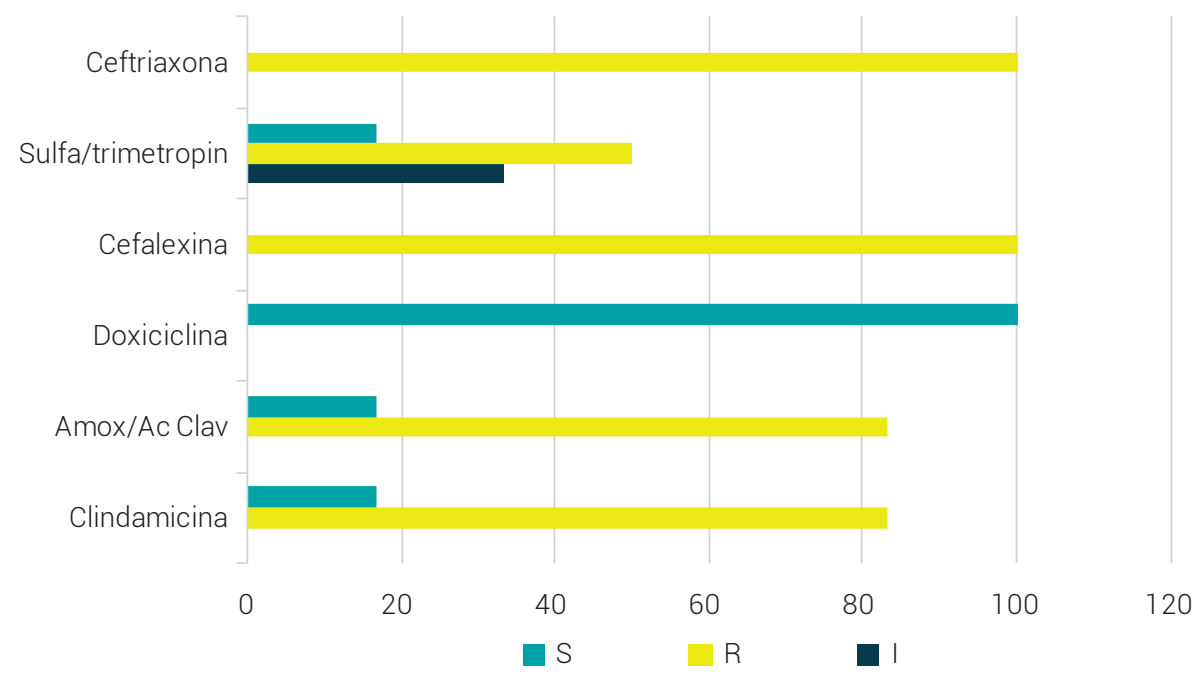

Figura 4. Perfil de sensibilidad de muestras identificadas con Staphylococcus epidermidis aislado de muestras de pioderma canino en la ciudad de Popayán Fuente: elaboración propia

Al analizar los antibióticos evaluados, en términos generales, se observó una mayor resistencia frente a clindamicina, cefalosporinas y amoxicilina con ácido clavulánico (tabla 1).

Tabla 1. Patrón de resistencia de los 34 aislados de muestras de pioderma canino frente a los antibióticos evaluados.

\begin{tabular}{lcc}
\hline \multicolumn{1}{c}{ Antimicrobiano } & Número & Porcentaje \\
\hline Clindamicina & 23 & $68 \%$ \\
\hline Cefalexina & 23 & $68 \%$ \\
\hline Amoxicilina/Ac. Clavulánico & 20 & $59 \%$ \\
\hline Ceftriaxona & 19 & $56 \%$ \\
\hline Trimetoprim/sulfametoxazol & 13 & $38 \%$ \\
\hline Doxiciclina & 8 & $23 \%$ \\
\hline
\end{tabular}

Fuente: elaboración propia 


\section{Discusión}

El pioderma canino es una presentación común en la práctica de pequeños animales [2]. Dentro de los agentes etiológicos, bacterias del género Staphylococcus pueden causar una gama amplia de infecciones oportunistas, desde pioderma leve hasta infecciones necrotizantes rápidamente fatales [13]. En este contexto, el papel de los estafilococos coagulasa positivos en pioderma es bien reconocido [6]. Las especies más importantes son S. pseudointermedius, S. aureus, y S. schleiferi spp. coagulans, donde $S$. pseudointermedius es el agente aislado primariamente en caninos [13, 14] como han reportado diferentes autores, con una ocurrencia desde el $26 \%$ hasta el $94,8 \%[9,15,16]$, similar a los hallazgos de este estudio. Esta condición se debe a su característica de microorganismo comensal de mucosas y piel, sumado a factores inmunológicos y ambientales [17].

Otros estafilococos residentes de la microbiota de la piel de los caninos incluye coagulasa negativos como S. epidermidis [18], a pesar de que esta especie no se asocia con la ocurrencia de pioderma, alteraciones en el equilibrio de la microbiota puede favorecer el aumento de la población de dicho microorganismo lo que lleva a la aparición de infecciones cutáneas. S. aureus, S. schleiferi y S. hyicus tienen una baja taza de ocurrencia en caninos, involucrados hasta en un $10 \%$ de los casos $[4,6]$.

El canino es una especie susceptible a la presentación de pioderma, probablemente por factores anatómicos puesto que el estrato córneo es más delgado, carece de lípidos en el folículo y tiene un pH más alto [3]. Por otro lado, la literatura reporta que perros de razas de pelo largo son las más afectadas. Sin embargo, en los resultados del presente estudio, si bien la mayoría de los casos fue de perros mestizos, caninos de razas de pelo corto como pitbull, beagle, sharpei, entre otros, fueron afectados, similar a un estudio realizado en la ciudad de Bogotá [19].

Otras condiciones como la edad, sexo o raza no se consideran factores predisponentes para su presentación [20], a pesar de que la mayoría de los casos de pioderma en este estudio se dieron en animales jóvenes, reportado también por otros autores con una prevalencia del 50 \% en menores de un año [21]. La proporción en hembras fue más alta, similar a otros estudios realizados en Colombia [19].

El control del pioderma requiere terapia antibiótica tópica o sistémica [4]. Dentro de los fármacos de primera elección están antibióticos de amplio espectro como clindamicina, cefalexina, amoxicilina con ácido clavulánico y como alternativa están doxiciclina, sulfas potenciadas con trimetoprim, lincomicina y eritromicina [4, 13]. Dado que anteriormente el tratamiento raramente representaba un desafío, el uso frecuente de estos antibióticos de amplio espectro probablemente llevó al surgimiento de patógenos resistentes [6]. Diferentes autores han documentado la resistencia de 
estafilococos aislados de pioderma, en particular, S. pseudointermedius, predominantemente a antibióticos betalactámicos como cefalosporinas de primera generación, amoxicilina/ácido clavulánico y ampicilina [5, 8, 9, 22].

A pesar de que el mecanismo de resistencia de los estafilococos a la meticilina es el más reportado, y que es transmitido por el gen mecA, que codifica una proteína de unión a la penicilina alterada (PBP2a), la producción de esta proteína de unión a penicilina alterada hace que la resistencia a todos los derivados de b-lactámicos, incluidas las penicilinas, las penicilinas potenciadas, las cefalosporinas y los carbapenémicos [8], comportamiento revelado por los estafilococos identificados en el presente estudio.

Adicionalmente, los estafilococos también han adquirido resistencia a antibióticos diferentes al grupo de los betalactámicos, como a los macrólidos, lincosamidas, sulfas potenciadas y tetraciclinas [6, 8]. En este caso, la resistencia a clindamicina, puede ser atribuída al gen msrA, que codifica el flujo de salida antimicrobiano, o los genes erm, que codifican los cambios en el sitio diana antimicrobiano ribosómico [8]. Tal resistencia puede ser entre el $28 \%$ hasta el $72 \%$ en los aislados principalmente para S. pseudointermedius $[5,9,15,22]$. Respecto a sulfas potenciadas con trimetoprim el mecanismo de resistencia generado por los estafilococos se debe al cambio estructural de la dihidropteroato sintetasa que produce una enzima con menor afinidad por la sulfonamida [23] o por la presencia del gen dfrK [24]. Los índices de resistencia en los aislados varían entre el 29 \% hasta el 56 \% [5, 9, 25, 26]. En nuestro estudio se evidenció una resistencia significativa para los anteriores antibióticos no solamente para S. pseudointermedius, sino también para S. epidermidis. Respecto a las tetraciclinas los mecanismos de resistencia comprenden bombas de eflujo, alteración del sitio de acción en el ribosoma mediado por el gen tetM, mecanismo de resistencia generado para doxiciclina [6]. A pesar de que no hace parte de los antibióticos de primera elección para tratamiento de pioderma, y el hallazgo de resistencia en las muestras del presente estudio es relativamente bajo (8=23\%), es un aviso para racionalizar su uso y así evitar llegar a índices de resistencia mayores.

\section{Conclusiones}

El uso indiscriminado de antibióticos y su marcada resistencia se ve claramente reflejado los resultados obtenidos, principalmente en betalactámicos.

El uso de pruebas específicas como los cultivos y antibiogramas fue de gran ayuda para el tratamiento de aquellos pacientes que iban a empezar su tratamiento para esta anomalía. 
Staphylococcus pseudointermedius sigue siendo el agente más prevalente en pioderma canino, determinándolo en este trabajo y estudios anteriores.

\section{Referencias}

[1] Holm BR, Petersson U, Marner A, Bergstrom K, Franklin A, Greko C. Antimicrobial resistance in staphylococci from canine pyoderma: a prospective study of first-time and recurrent cases in Sweden. Veterinary Record. 2002; 151:600-5.

[2] Russell-Ortiz NP. Análisis de las indicaciones terapéuticas para el pioderma canino por Staphylococcus pseudointermedius. [Tesis de grado]. [Santiago de Chile]: Universidad de Chile; 2014. [Citado 2019 marzo 20]. Disponible en: http://repositorio.uchile.cl/bitstream/ handle/2250/132028/An\%C3\%Allisis-de-las-indicaciones-terape\%C3\%BAticas-para-elpioderma-canino-por-Staphylococcus-pseudintermedius. pdf?sequence=1\&isAllowed=y.

[3] Gortel K. Recognizing Pyoderma More Difficult than it May Seem. Vet Clin Small Anim. 2013; 115:431-18. doi: 10.1016/j.cvsm.2012.09.004

[4] Sykes JE. Staphylococcus Infection. En: Sykes JE. Canine and Feline infectious diseases. St. Louis, Missouri: Elsevier Saunders; 2014. 925p.

[5] Escribano C, Ordeix L, Pol G, Puigdemont A, Brazis P. Patrones de sensibilidad de Staphylococcus pseudointermedius aislados de infecciones cutáneas en el perro. Revista Centro Veterinario. [Internet]. 2010. [Citado 2019 marzo 20]. Disponible en: http://axonveterinaria.net/web_axoncomunicacion/centroveterinario/40/cv_40_Staphylococcus_pseudintermedius.pdf

[6] Loeffler A, Lloyd DH. What has changed in canine pyoderma? A narrative review The Vet. J. 2018; 235:73-82. doi: 10.1016/j.tvjl.2018.04.002

[7] Organización Mundial de la Salud. Resistencia a los antimicrobianos. [Internet]. 2017. [Citado 2019 marzo 20]. Disponible en: https://www.who.int/antimicrobial-resistance/es/

[8] Cain LC. Antimicrobial Resistance in Staphylococci in Small Animals. Vet Clin Small Anim. 2013; 43(1):19-40. doi: 10.1016/j.cvsm.2012.09.003

[9] Ruzauskas M, Couto N, Pavilonis A, Klimiene I, Siugzdiniene R, Virgailis M, Vaskeviciute L, Anskiene L, Pomba C. Characterization of Staphylococcus pseudintermedius isolated from di- 
Perfil de sensibilidad in vitro de Staphylococcus spp. aislados de muestras en pioderma canino en la ciudad de Popayán

seased dogs in Lithuania. Polish Journal of Veterinary Sciences. 2016; 19(1):7-14. doi: 10.1515/ pjvs-2016-0002

[10] Quinn PJ, Markey BK, Leonard FC, FitzPatrick ES, Fanning S. Hartigan PJ. Veterinary Microbiology and Microbial Diseases. 2da edición. Oxford, UK.: Blackwell Science; 2011. $1243 p$.

[11] Markey BK, Leonard FC, Archambault M, Cullinane A, Maguire D. Clinical Veterinary Microbiology. 2da edición. Saint-Hyacinthe, Canada: Mosby Elsevier; 2013. 915p.

[12] Clinical and Laboratory Standards Institute. Performance Standards for Antimicrobial Susceptibility Testing. Clinical and Laboratory Standards Institute (NCCLS). Fifteenth Informational Supplement. CLSI/NCCLS document M100-S15. [Internet]. 2017. [Citado 2019 marzo 20]. Disponible en: https://clsi.org/media/1469/m100s27_sample.pdf

[13] Greene CE. Staphylococcal infections. Greene CE. Infectious diseases of the dog and cat. 4th ed. St. Louis: Elsevier Saunders; 2012. p.383-9.

[14] Miller WH. Bacterial skin diseases. En: Muller \& Kirk's small animal dermatology. Miller WH, Griffin CE, Campbell KL, editors. 7ma. edición. St. Louis: Elsevier Saunders; 2013. P. 184-222.

[15] Giacoboni GI, Vinocur F, Fauret N, Grandinetti J, Manzuc P. Detección de Staphylococcus pseudintermedius resistentes a meticilina y a otros antimicrobianos de uso habitual en la clínica en piodermias caninas. Analecta Vet. 2017; 37(2):19-24. doi: 10.24215/15142590e012

[16] Romero MF. Determinación preliminar de los patrones de resistencia antimicrobiana de las bacterias pertenecientes al género Staphylococcus spp. Causantes de pioderma en pacientes caninos atendidos en clínicas veterinarias del Área Metropolitana. [Tesis grado]. [Costa Rica]: Universidad Nacional; 2014. Disponible en: https://core.ac.uk/download/pdf/48880679.pdf

[17] Bannoehr J. Guardabassi L. Staphylococcus pseudintermedius in the dog: taxonomy, diagnostics, ecology, epidemiology and pathogenicity. Vet Dermatol. 2012; 23(4): 253-e52. doi: 10.1111/j.1365-3164.2012.01046.x

[18] Schmidt VM, Williams NJ, Pinchbeck G, Corless CE, Shaw S, McEwan N, Dawson S, Nuttall T. Antimicrobial resistance and characterisation of staphylococci isolated from healthy Labrador retrievers in the United Kingdom. BMCVetRes. 2014;10(17):3-14.doi:10.1186/1746-6148-10-17

[19] Castellanos OL, Rodríguez GM, Santos RA. Aislamiento e identificación bioquímica de microorganismos bacterianos a partir de infecciones de piel en caninos. Rev. Med. Vet. [Internet]. 
2011 [citado 2019 marzo 20]; 22:21-30. Disponible en: http://www.scielo.org.co/pdf/rmv/n22/ n22a03.pdf

[20] Seckerdieck F, Mueller RS. Recurrent pyoderma and its underlying primary diseases: a retrospective evaluation of 157 dogs. Vet. Record. 2018; 182(15):434. doi: 10.1136/vr.104420.

[21] Balazs MV. Pioderma en el canino. Rev. Electrón. Vete. [Internet]. 2012 [citado 2019 marzo 20]; 13(3): 1-35. Disponible en: https://www.redalyc.org/articulo.oa?id=63623410016

[22] Huerta B, Maldonado A, Ginel PJ, Tarradas C, Gómez-Gascón L, Astorga RJ, Luque I. Risk factors associated with the antimicrobial resistance of staphylococci in canine pyoderma Vet. Mic. 2011; 150(3-4): 302-8. doi: 10.1016/j.vetmic.2011.02.002

[23] Zinner SH, Mayer KH. 33 - Sulfonamides and Trimethoprim. En: Bennett JE, Dolin R, Blaser MJ. Mandell, Douglas, and Bennett's Principles and Practice of Infectious Diseases. 8va. edición. Volume 1. Philadelphia: Elsevier Saunders; 2015. p. 410-418.

[24] Kadlec K. Schwarz S. Identification of the Novel dfrK-Carrying Transposon Tn559 in a Porcine Methicillin-Susceptible Staphylococcus aureus ST398 Strain. Antimicrobial agents and chemotherapy. 2010; 54(8):3475-7. doi: 10.1128/AAC.00464-10

[25] González-Domínguez MS, Carvajal HD, Calle-Echeverri DA. Chinchilla-Cárdenas D. Molecular Detection and Characterization of the mecA and nuc Genes From Staphylococcus Species (S. aureus, S. pseudintermedius, and S. schleiferi) Isolated From Dogs Suffering Superficial Pyoderma and Their Antimicrobial Resistance Profiles. Front Vet Sci. 2020; 7:1-11. doi: 10.3389/fvets.2020.00376

[26] Vigo GB, Giacoboni GI, Gagetti PS, Pasteran FG, Corso AC. Resistencia antimicrobiana y epidemiología molecular de aislamientos de Staphylococcus pseudintermedius de muestras clínicas de caninos. Rev. Argent. Microbiol. 2014; 47(3):206-11. doi: https://doi.org/10.1016/j. ram.2015.06.002 